\title{
Optimization of Mechanical Crimping in the Terminal Crimping Process Using a Response Surface Methodology
}

\author{
Kaona Jongwuttanaruk (iD) and Chalermsak Thavornwat $(\mathbb{D}$ \\ Department of Industrial Engineering, Faculty of Engineering, Rajamangala University of Technology Thanyaburi, Pathum, \\ Thani 12110, Thailand \\ Correspondence should be addressed to Chalermsak Thavornwat; chalermsak_t@rmutt.ac.th
}

Received 11 October 2021; Accepted 13 January 2022; Published 2 February 2022

Academic Editor: Aniello Riccio

Copyright (C) 2022 Kaona Jongwuttanaruk and Chalermsak Thavornwat. This is an open access article distributed under the Creative Commons Attribution License, which permits unrestricted use, distribution, and reproduction in any medium, provided the original work is properly cited.

\begin{abstract}
This research aims to optimize the tensile mechanical properties in the terminal crimping process in the terminal 064 series using central composite designs (CCD) of response surface methodology (RSM) on pull force using the Minitab 18 Program. Pull force testing is the mechanical property of the indicator in the crimping process. Three independent variables of the crimp dimensions were studied, including crimp height, crimp depth, and crimp width. The optimum crimp dimensions to sustain a maximum impact pull force of $13.60 \mathrm{Kgf}$ were a crimp height of $1.25 \mathrm{~mm}$, crimp depth of $2.36 \mathrm{~mm}$, and crimp width of $1.48 \mathrm{~mm}$ for a compaction ratio of $18.63 \%$. The tolerance on the crimp height of $0.05 \mathrm{~mm}$ maintained the compaction ratio within the SAE/ USCAR-21 Revision 4 standard compaction range of 15 to $20 \%$. This specification requires three consecutive crimp heights to pass electrical and mechanical tests. Using samples built to this compaction range provides the best opportunity to pass such tests whilst also addressing the problem of loose wire strands for a pull force of more than $8 \mathrm{Kgf}$. Finally, an optimization analysis is carried out to select the finest conditions for the process.
\end{abstract}

\section{Introduction}

Automotive companies operate in increasingly competitive environments. Regardless of their size and whether they are working in the autoassembling or feeding industry, they are under market pressure to provide the highest quality products at a lower cost [1]. Companies that fail to improve quality, productivity, and customer satisfaction face a bleak future from competitors taking their market share, which can lead to heavy financial losses [2]. Every electronic device or electrical machine has characteristic operational requirements. Although the design of wire harnesses for these devices and machines may vary greatly depending on the application, the three core components of a wire harness are the same: a wire harness assembly consists of connectors, terminals, and wires. The types of connectors and terminals chosen are very important in the design and manufacture of wire harnesses $[3,4]$ Moreover, the different types of connectors and terminals used govern the performance, stability, and dependability of the harness. In general [5], the different types of wire harnesses include

automotive wire harnesses,

body wiring harnesses,

electrical wire harnesses, as used in pumps, telecom machines, and other heavy machinery,

electronic wire harnesses, as used in TVs, computers, and all types of electronic gadgets,

engine wiring harnesses, and

chassis wiring harnesses.

The design of the connectors is related to their functioning and performance. The durability, materials used, insulation between pins, and ease of connection are governed by the setting in which the connectors will be used. As connectors must accommodate various functions under different conditions, their design can vary greatly across a wide range of applications, from connecting to consumer 
goods, medical devices, aerospace equipment, defence hardware, and automotive components. The shapes and sizes of the connectors are thus designed based on the requirements of the device or machine [6].

Terminals are an essential component of wire harnesses, terminating a conductor in a specific way to secure and safeguard the electromagnetic connection. Terminals for wire harnesses are generally made of metals or alloys and may be combined with other materials such as silicon and carbon. Terminals come in a range of different designs, sizes, and shapes. Depending on the type of connection and wire harness, terminals may be shaped into hooks, spades, rings, quick-disconnects, butts, bullets, and flags. Each wire harness application is unique and designed for a specific operation with its own set of constraints and grouping of signals. Choosing the right connector and terminal for an operation is crucial to the overall performance of the wire harness [7].

Terminal section measurement and analysis using image processing have been widely applied to harness quality detection, but standard approaches are not satisfactory for automatic recognition of the terminal contour. Image segmentation technology has now advanced to enable calculation of the terminal contour [8] in a nondestructive way, with the development of a system for the automatic detection of quality and reporting of output [9]. Image processing is unsatisfactory for automatic detection of crimp contour quality but then state a system has been developed to do just that.

Terminal conductor crimp size consists of crimp height $(X)$, crimp depth $(Y)$, and crimp width $(Z)$ measured from the top and side surfaces of the crimp formation to the base radial surface as shown in Figure 1 (extrusion points are not shown in this configuration). Measuring crimp size in this fashion is a quick, nondestructive method to help verify correct metallurgical compression of a terminal around the wire's conductor and as such is an excellent approach for process control. Crimp size specification is typically set to balance the electrical and mechanical performance over the complete range of wire strands, coatings, terminal materials, and plating. While it is possible to optimize the crimp height for individual wire strands and terminal plating, only one specification for crimp size is normally created [10].

Once a good crimp is established and proven using other methods, measurement of the total crimp height for the specific terminal, wire, and tooling combination offers a useful reference value. Subsequent crimps can be measured and compared to the reference value to determine if the crimp was properly set. The crimp height measurement identifies tooling wear, setup mistakes, or press inconsistency and has the advantage of being nondestructive, which is suitable for spot testing a production run without any scrapping of materials. However, crimp height measurement is time-consuming and is not easily automated without the use of expensive camera-based systems. Further, the performance of the measurement requires a sufficient level of operator skill to obtain consistent results, so training is required to achieve consistency [11].
In the process of assembling a wire harness, testing the suitability of a crimped terminal is crucial. If the terminal is not properly attached to the end of the wire, it can cause the wire (and eventually the entire wire harness) to fail. Most manufacturers use pull testing to assess crimped connections and ensure that terminals are properly attached, as shown in Figure 2.

Pull testing measures the amount of pull force required to separate a crimped terminal from a wire. An amount of force should be applied more than $8 \mathrm{Kgf}$ to avoid the chance of product failure. To perform a pull test, one end of the wire is fed into the gripping attachment, while the other end is secured to a fixed point. The tester then pulls the wire at a gradual pace, increasing the force until the wire breaks or the terminal is removed. The speed at which the wire is pulled depends on the wire, terminal, and application standards. For example, USCAR-21 specifies that the wire should be pulled at a rate of 50 to $250 \mathrm{~mm}$ per minute. When performing the pull test, the tester records the amount of force to remove the terminal. By pulling the wire at a constant rate, the tester can pinpoint the peak force needed to remove the terminal from the wire.

A crimped connection is considered serviceable if the terminal is removed at a force acceptable for the intended application. The acceptance criterium varies depending on the terminal and the size of the wire. Less force is stipulated to pull a terminal from a thin wire than a thicker one. For example, according to UL standard 486A, it should take 1.5 pounds of force to pull a terminal from a 30 AWG wire, while it takes 70 pounds of force to pull a terminal from a 12 AWG wire.

Pull-force testing enables manufacturers to properly calibrate the crimping tool by providing data on the strength of the connection and any damage that may have occurred in the crimping process [12].

In the current study, an analysis response surface design was used to model curvature in pull-force data to identify crimp settings that optimized pull-force response [13]. As is typical for response surface design, a factorial or fractional factorial experiment was performed to identify the most important factors in the crimp process for eliminating defects and improving the quality of the crimp process.

\section{Literature Review}

The theory and practice of response surface methodology (RSM) are studied and reflected in many published studies. Zaidon et al. [14] used RSMs to optimize processing variables for high polymer loads in compressed wood. The RSM was used to optimize processing variables to achieve high polymer loading in compressed sesenduk wood (Endospermum diadenum). In this study, RSM and three process variables, namely, the phenol-formaldehyde concentration (PC), precuring time (PCT), and compression ratio (CR) of the central composite design (CCD), were used to optimize the loading of these variables in the polymer. Through this design, a secondary polymer loading model was obtained. The experimental value was in good agreement with the predicted value, the model was highly significant, and the 


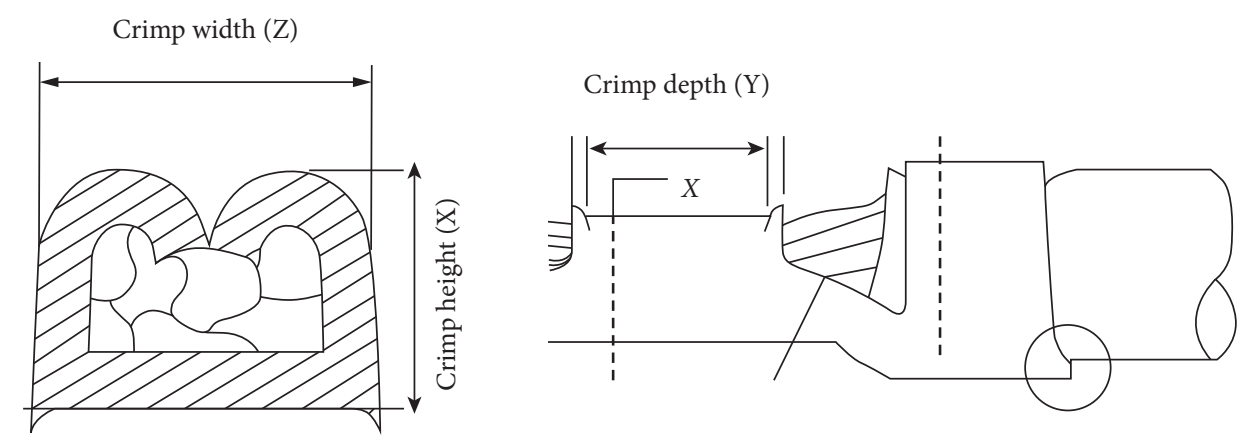

Figure 1: Crimp dimension measurement.

correlation coefficient was 0.915 . During the precuring time used in this study, the independent variable had no significant effect on the polymer loading. The interactions between PC and PCT, PC and CR, and PCT and CR were negligible. The following were used to achieve maximum polymer loading: a $36 \%$ phenol-formaldehyde solution and a $74 \%$ compression ratio.

Omolola et al. [15] used the RSM to study the optimization of the microwave drying conditions of the banana varieties Luvhele and Mabonde. Drying with a composite rotating center design, there are two variables: Luvhele's microwave power $(100,200$, and $300 \mathrm{~W})$ and its drying time (40, 26, and 12 minutes; 100, 200, and $300 \mathrm{~W}$; and 42, 27, and 12 minutes) for Mabonde. Further, they used analysis of variance and regression analysis to analyze color and texture (hardness) data. The fit of the obtained models was very good because the lack of fit of each model was insignificant. The coefficient of determination R2 of the model was relatively high. Thus, the model obtained for the response was sufficient and acceptable. They found that the best drying conditions for the Luvhele variety were $178.76 \mathrm{~W}$ and 12 minutes with convenience of 0.91 , while those of the Mabonde variety were 127.67 $\mathrm{W}$ and 12 minutes with an expected value of 0.86 . The results of this study can be used as a standard for microwave processing of Luvhele and Mabonde banana varieties. In a study by Hong et al. [16], interference experiments were conducted under various uneven profile friction conditions generated by combining moulds and samples with different surface conditions. The experiment adopted an RSM and three-level full factorial design and established experimental points according to the experimental results as regression. By using pointer variables and different qualitative parameters, a regression model was constructed from a secondary model with interactive components. In addition, a general regression model including friction isotropy and anisotropy was established to predict the plastic deformation of the material after inversion. Using DEFORM3D software for finite element analysis, the validity of the general regression model for forging deformation was verified. The simulation results verify the consistency between the observed finite element analysis and the experimental results, and the model predicts the reliability of the nonuniform friction mode. Rosa et al. [17] studied the compression behaviour of steel fibber concrete (SFRC) in detail, thus highlighting the differences in the fibber addition effects. In this study, the compression

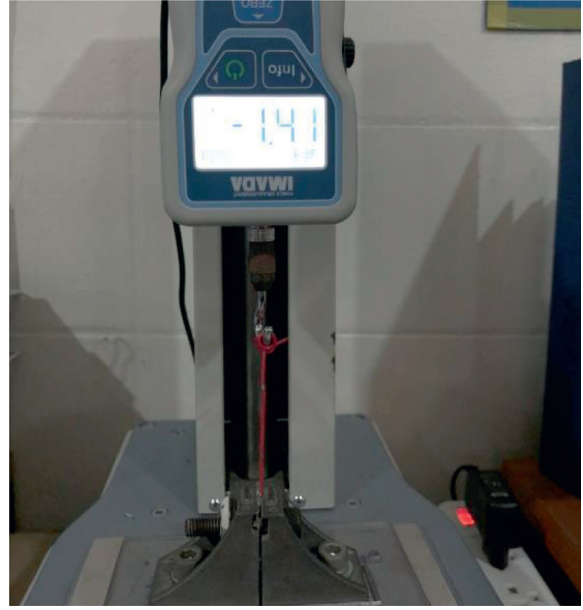

FIgURE 2: A pull testing setup to measure the pull force required to separate a crimped terminal from a wire.

behaviour of SFRC was studied in detail. Additionally, a database was created for this purpose, which includes 197 tests on cylindrical concrete specimens with a size of $150 \times 300 \mathrm{~mm}^{2}$ (diameter $\times$ height). Through the RSM, we revealed the relationship between the geometric parameters (length, diameter, and aspect ratio) of the fibres, their number (volume fraction), and some matrix parameters (compressive strength and maximum size). Coarse aggregate and SFRC have different responses to compression, namely, strength, elastic modulus, critical deformation under maximum load, and volumetric deformation work of prepeak and postpeak branches. We used a linear polynomial model to fit each response with defined factors and study variables in dimensional and nondimensional formats. The results obtained verify that the addition of steel fibres can significantly improve the ductility and energy absorption capacity of concrete and simultaneously significantly increase the volumetric deformation work of the front and rear supports. The peak is associated with a matrix without fibres. In addition, a new model that describes the stress-strain curve of the compressive behaviour of SFRC based on greater ductility and energy absorption was analyzed. The characteristic of this model is the presence of softening branches after the maximum load determined by the residual compressive strength. This parameter corresponds to a value of compressive stress related to a deformation equal to three times 
the maximum value of the curve; that is, it depends significantly on the aspect ratio and the fibre content. Kumar et al. [18] used the RSM to analyze the freshness and hardening properties of concrete containing E-waste plastic, namely, high-impact polystyrene (HIPS), as a partial substitute for coarse aggregate. In this study, a multifaceted center composite response surface design was used. A statistical model was established between these factors (HIPS and water-cement ratio) and their response variables (settling, fresh density, dry density, compressive strength, shed tensile strength, and bending strength). The Design Expert 9.0.3 software package was used to analyze experimental values, establish relationships, and develop the final mathematical model based on the factors coded from the predicted response. The influency of factors on all variable attributes can be visually observed in the response surface and contour plots. Experimental verification shows that the experimental values are in good agreement with the predicted values, which verifies the desirability of the calculated response surface model $=1$. Replacing HIPS affected all the properties and water-cement ratio of concrete. Although various properties had a downward trend, the empirical and predictive values show that HIPS, which is expected to be used as a coarse aggregate in concrete, achieves a certain replacement rate, thereby gradually reducing harmful solids through exhaustion and waste and protecting natural resources. Garlapati et al. [19] showed that the tableting process has an incomprehensible impact on the appearance, content uniformity, hardness, thickness, friability, disintegration time, and dissolution time of the tableting process. Among all the parameters of the tablet press, the speed of the feeder, precompression, main compression force, and speed of the turntable have a significant effect on the characteristics of the tablet. The objective of this study was to use statistical modelling and optimization methods to model and optimize the compression process of levocetirizine tablets using response surface methods [20]. By adopting the speed of the turret and front and rear stages, a 3-stage center composite design was selected. The main compression force and feeder speed were used as input variables, and the tablet characteristics (hardness, thickness, and disintegration time) were used as output variables. A nonlinear regression model corresponding to the output variables (hardness, thickness, and disintegration time) was obtained. The R2 values of hardness, thickness, and disintegration time were $99.26 \%$, $98.01 \%$, and $99.84 \%$, respectively. The effects of simple terms, square terms, and interaction terms on the hardness, thickness, and disintegration of the table surface are summarized through the significance test and are described in the response surface graph. Using a turret speed of $68 \mathrm{rpm}$, main compression and precompression forces of 2.05 and $7.95 \mathrm{kN}$, respectively, and a feed rate of $27 \mathrm{rpm}$, the tableting process variables predict a hardness of $15.3 \mathrm{kPa}$, thickness of $3.7 \mathrm{~mm}$, and a disintegration time of $226 \mathrm{~s}$ to optimize the tablet performance. The results demonstrate the reliability of the proposed statistical method to model and optimize the compression study of levocetirizine tablet formulations. This research helps to increase the compression rate of the tablets during the formulation of levocetirizine tablets.

\section{Materials and Methods}

The mechanical strength of the crimping assembly was closely related to the indentation depth. Although a large number of crimping tools with different brands and diversified styles have emerged in the industry in recent years, most manufacturers only refer to a rough crimping specification for the design of indentation depth corresponding to different specific combinations of contacts and strands in the initial stage of product development as Figure 3. To form the final product design specification in line with the industry standard, it is necessary to supplement a large number of pull-force tests of the crimping assembly in the later stage.

Wire strands were crimped into the terminal 064 series (Figure 4) to obtain loose strands and to affect less than the standard pull force of $8 \mathrm{~kg}$ as measured by a digital force gauge (Imada: DST-500N IMADA).

In the crimping process, the strength of the crimp and the current-carrying capability may be greatly reduced if not all the wire strands are fully enclosed in the conductor crimp section. To obtain a good crimp, the crimp height should be met as specified by the connector manufacturer. If all the strands do not contribute to the crimp height and thus crimp strength, then the crimp will not perform to specifications. Generally, the problem of loose wire strands is very easy to solve by simply gathering the wires together before inserting them into the terminal to be crimped. The wires should be gathered with open wings with the core exposed or folded down into the core, but not touching (i.e., not locked), as shown in Figure 5.

The study of optimum conditions using the RSM is an experiment to determine the optimum conditions of the responses, which is a process that uses mathematical and statistical knowledge for designing the experiments, and it is widely applied in scientific and industrial research fields. In addition, the RSM has 2 popular experimental designs, namely, the Box-Wilson experimental design and Box-Behnken design. The Box-Wilson experimental design is commonly used because it can resolve the problems of the $3^{n}$ factorial design used for multivariate quantitative studies, and its experiments cover more than the Box-Behnken design, which requires numerous experimentations for $3^{n}$ factorial designs. To reduce the number of experiments, [21] developed the central composite design (CCD) from the $2^{n}$ factorial design. The CCD, therefore, increased the accuracy of the factorial experiment at the center and axial points, dividing into 5 levels, lowest $(-\alpha)$, low $(-1)$, medium (0), high $(+1)$, and highest $(+\alpha)$ [22], to form a curvilinear or second-order model, and the CCD has $2^{n}+(2 n+6)$ experiments for experiment with four factors or independent variables. To enhance the efficiency of a crimped terminal to pull force, the Minitab 18 Program was used in central composite designs (CCD) using a response surface methodology (RSM) with a model dependent on 3 factors: crimp height $(X)$, crimp depth $(Y)$, and crimp width $(Z)$ [23-25]. Table 1 shows the crimp parameters used in the experiment, for which 20 generalized response surface models were run, including 10 factorial design runs, 5 axial points, and 10 replicates at the center points [26]. 


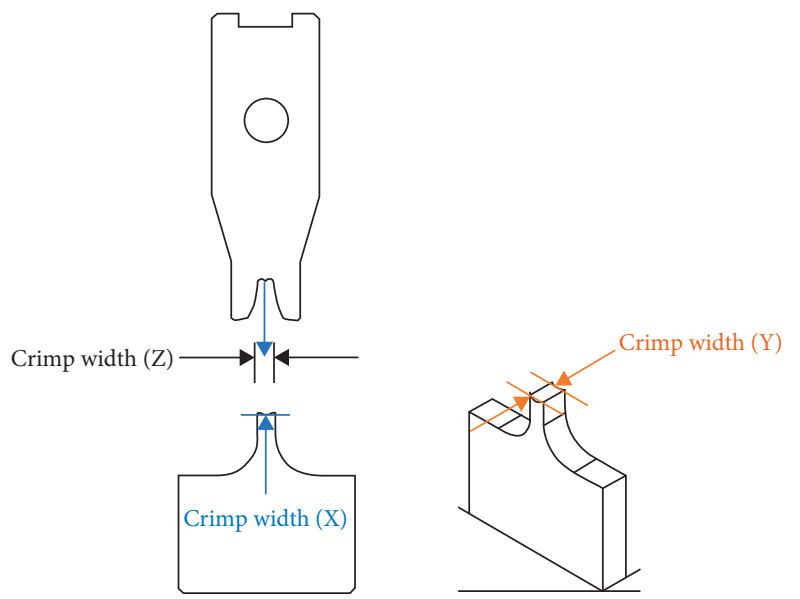

Figure 3: Crimpers and Anvil for crimping assembly.

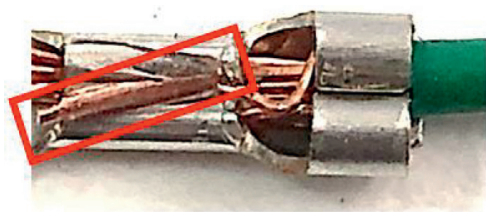

FIgURE 4: Wire strands lose.

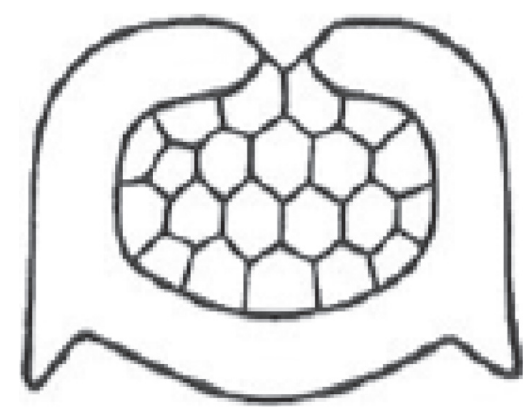

FIGURE 5: Open wings with core exposed or folded down into core but not touching (i.e., not locked).

The Minitab worksheet displays a portion of the central composite design. The tester performs the experiment by collecting data using the order shown in the RunOrder column. Following data collection, the tester enters the response data in an empty column in the worksheet and analyzes the design $[27,28]$, as shown in Table 2.

\section{Results and Discussion}

ANOVA can be useful in determining the significance of the linear, quadratic, and 2-way interaction terms involving crimp height $(X)$, crimp depth $(Y)$, and crimp width $(Z)$. The significance of each term in the quadratic model is shown in Tables 3 and 4, with terms considered significant for $P$ values less than 0.05. An F-test was performed to ensure the fitness of the models and to predict variation. The lack of fit test was not significant, with all $\mathrm{F}$ values greater than 0.05 , demonstrating the suitability of the model.
TABle 1: Parameters for experimental design.

\begin{tabular}{llll}
\hline Factor & & Variation \\
& Low $(-1)$ & Med. $(0)$ & High $(+1)$ \\
\hline Crimp height $(X)$ & $1.15 \mathrm{~mm}$. & $1.25 \mathrm{~mm}$. & $1.35 \mathrm{~mm}$. \\
Crimp depth $(Y)$ & $1.96 \mathrm{~mm}$. & $2.36 \mathrm{~mm}$ & $2.75 \mathrm{~mm}$. \\
Crimp width $(Z)$ & $1.37 \mathrm{~mm}$ & $1.48 \mathrm{~mm}$. & $1.59 \mathrm{~mm}$. \\
\hline
\end{tabular}

TABLE 2: Experimental design and results.

\begin{tabular}{lccc}
\hline \multicolumn{4}{c}{ Variables (real value) } \\
Crimp height & $\begin{array}{c}\text { Crimp depth } \\
(X)\end{array}$ & $\begin{array}{c}\text { Crimp width } \\
(Z)\end{array}$ & $\begin{array}{c}\text { Response } \\
\text { avg. }\end{array}$ \\
\hline 1.15 & 1.96 & 1.37 & 7.30 \\
1.35 & 1.96 & 1.37 & 6.85 \\
1.15 & 2.75 & 1.37 & 7.30 \\
1.35 & 2.75 & 1.37 & 7.35 \\
1.15 & 1.96 & 1.59 & 7.24 \\
1.35 & 1.96 & 1.59 & 6.61 \\
1.15 & 2.75 & 1.59 & 7.01 \\
1.35 & 2.75 & 1.59 & 6.63 \\
1.08 & 2.36 & 1.48 & 5.70 \\
1.42 & 2.36 & 1.48 & 5.58 \\
1.25 & 1.69 & 1.48 & 9.65 \\
1.25 & 3.02 & 1.48 & 9.65 \\
1.25 & 2.36 & 1.30 & 8.75 \\
1.25 & 2.36 & 1.67 & 9.13 \\
1.25 & 2.36 & 1.48 & 13.62 \\
1.25 & 2.36 & 1.48 & 13.55 \\
1.25 & 2.36 & 1.48 & 13.59 \\
1.25 & 2.36 & 1.48 & 13.65 \\
1.25 & 2.36 & 1.48 & 13.39 \\
1.25 & 2.36 & 1.48 & 13.64 \\
\hline
\end{tabular}

The adjusted coefficient of determination (R-sq(adj)) for the crimp process was close to 1 , indicating that RSM is an effective tool for optimizing the pull force with respect to the crimping parameters and that the developed models were a good fit.

Response surface effects of the pull force as Figure 6 shows (a function of crimp height $(X)$, crimp depth $(Y)$, and crimp width $(Z)$ ) were visualized by drawing three-dimensional plots. Figure 7 shows the interaction of crimp depth $(Y)$ and crimp height $(X)$ against the impact strength.

Optimization of the crimp height $(X)$, crimp depth $(Y)$, and crimp width $(Z)$ to sustain maximum pull force was conducted. The optimum combination of values was a crimp height $(X)$ of $1.25 \mathrm{~mm}$, crimp depth $(Y)$ of $2.36 \mathrm{~mm}$, and crimp width $(Z)$ of $1.48 \mathrm{~mm}$, with a desirability value close to 1 , as shown in Figure 8.

After crimping, all wire strands have a shape that is no longer round, indicating that some degree of compaction has occurred. The crimp cross-sectional analysis system used to identify this phenomenon was composed of cutting and grinding integrated equipment, optical sampling, corrosion cleaning, a cross section image acquisition system, and wire harness terminal picture measurement to capture cross sections [29-32] as shown in Figure 9. 
Table 3: Analysis of variance.

\begin{tabular}{|c|c|c|c|c|c|}
\hline Source & $\mathrm{DF}$ & Adj SS & Adj MS & $\mathrm{F}$ value & $P$ value \\
\hline Model & 9 & 1766.97 & 196.33 & 1397.77 & $\leq 0.001$ \\
\hline Linear & 3 & 2.33 & 0.78 & 5.53 & $\leq 0.001$ \\
\hline Crimp height $(X)$ & 1 & 1.94 & 1.94 & 13.84 & $\leq 0.001$ \\
\hline Crimp depth $(Y)$ & 1 & 0.06 & 0.06 & 0.43 & 0.514 \\
\hline Crimp width $(Z)$ & 1 & 0.33 & 0.33 & 2.33 & 0.129 \\
\hline Square & 3 & 1762.85 & 587.62 & 4183.53 & $\leq 0.001$ \\
\hline Crimp height $(X)^{*}$ crimp height $(X)$ & 1 & 1258.10 & 1258.10 & 8957.07 & $\leq 0.001$ \\
\hline Crimp depth $(Y)^{*}$ crimp depth $(Y)$ & 1 & 339.47 & 339.47 & 2416.84 & $\leq 0.001$ \\
\hline Crimp width $(Z)^{*}$ crimp width $(Z)$ & 1 & 460.68 & 460.68 & 3279.84 & $\leq 0.001$ \\
\hline Two-way interaction & 3 & 1.79 & 0.60 & 4.24 & $\leq 0.001$ \\
\hline Crimp height $(X)^{*}$ crimp depth $(Y)$ & 1 & 0.73 & 0.73 & 5.18 & 0.024 \\
\hline Crimp height $(X)^{*}$ crimp width $(Z)$ & 1 & 0.44 & 0.44 & 3.13 & 0.078 \\
\hline Crimp depth $(Y)^{*}$ crimp width $(Z)$ & 1 & 0.62 & 0.62 & 4.42 & 0.037 \\
\hline Error & 190 & 26.69 & 0.14 & & \\
\hline Lack-of-fit & 5 & 19.31 & 3.86 & 96.87 & 0.531 \\
\hline Pure error & 185 & 7.38 & 0.04 & & \\
\hline Total & 199 & 1793.66 & & & \\
\hline
\end{tabular}

TABLE 4: Model summary.

\begin{tabular}{lccc}
\hline$S$ & R-sq (\%) & R-sq(adj) & R (\%)-sq(pred) \\
\hline 0.374779 & 98.51 & 98.44 & 98.33 \\
\hline
\end{tabular}

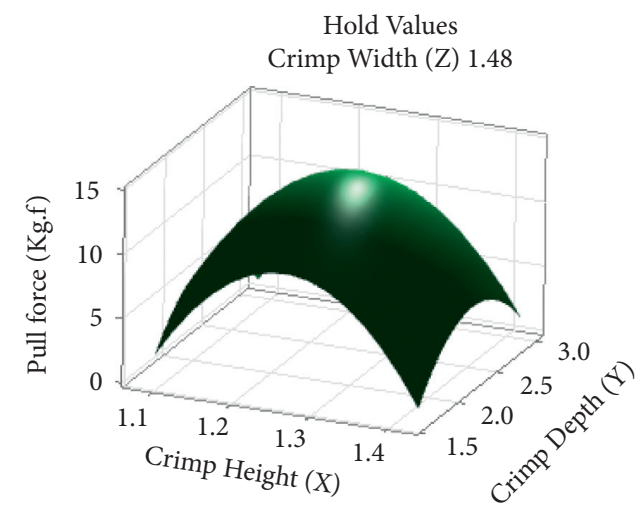

Figure 6: Surface plot of pull force versus crimp depth $(Y)$ and crimp height $(X)$.

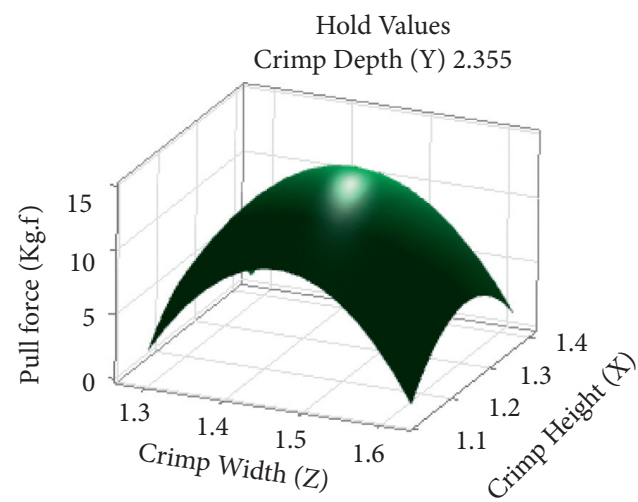

Figure 7: Surface plot of pull force versus crimp width $(Z)$ and crimp height $(X)$. 


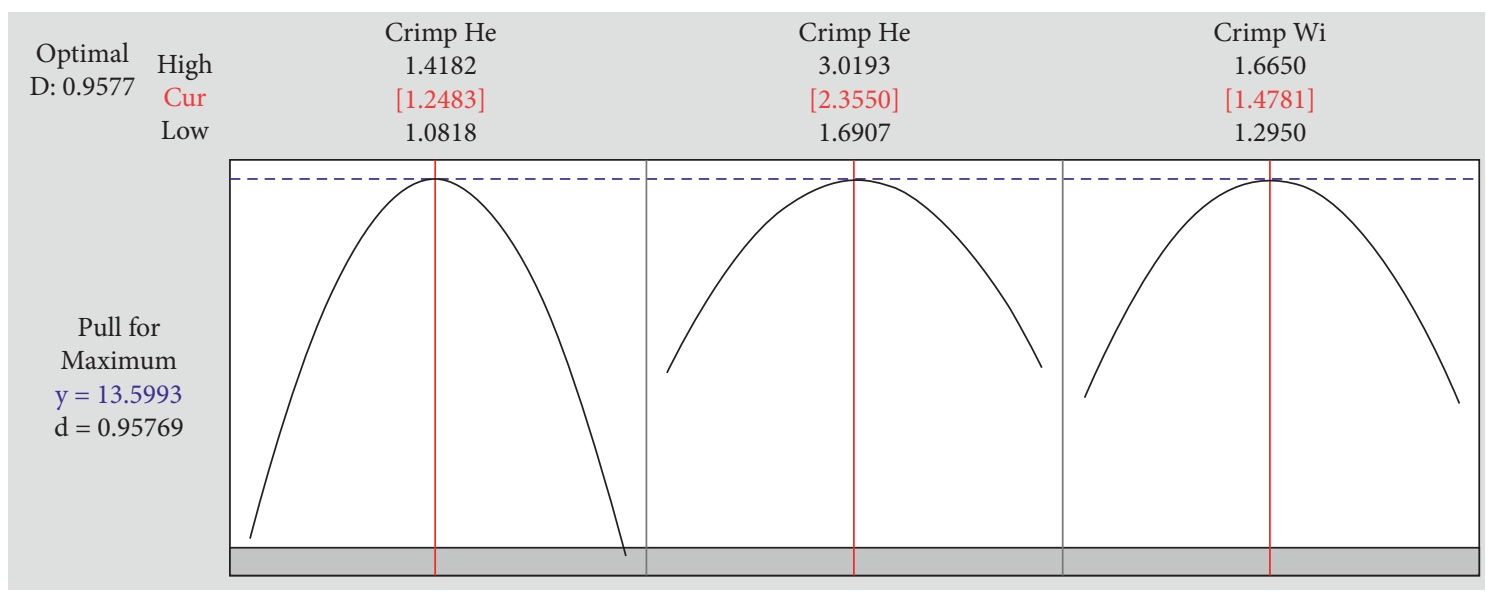

FIGURE 8: Optimum crimp parameters to sustain maximum impact pull force.

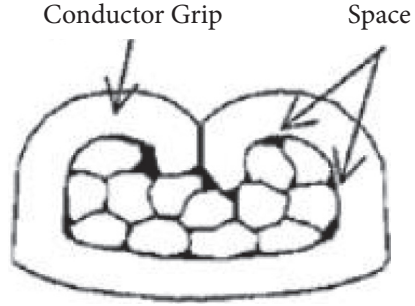

FIgURE 9: Crimp cross section.

Crimp dimensions were estimated using a compaction analysis. The compaction can be estimated using the following formula:

$$
\text { Compaction } \%=100\left(1-\frac{S_{1}}{S_{0}}\right),
$$

where $S_{1}$ is the cross-sectional area within the terminal conductor grip after crimping (including the space between the strands as in Figure 8), and $S_{0}$ is the cross-sectional area of the wire conductor.

Crimp quality is dependent on the amount of compaction and is controlled by the dimensions of the crimp tooling, terminal wings, and cable cross-sectional area. Consequently, it is important to note that the cable area used in production is consistent with the area of the cable used in the crimp design validation. Compaction is verified in production by terminal, cable, and crimp tool dimensions, which are usually controlled by specific tooling part numbers $[33,34]$. Figure 10 shows an optimum crimp with deformed strands that perfectly touch both each other and the wall of the contact. For the crimp in Figure 10, the compaction ratio was $18.65 \%$, and the pull force was $12.92 \mathrm{Kgf}$.

Figure 11 shows another optimum crimp with deformed strands that perfectly touch both each other and the wall of the contact, with a compaction ratio of $18.63 \%$ and pull force of $13.60 \mathrm{Kgf}$.

The crimp of Figure 12 shows the improper component distribution, under compressed strands, and gaps. The compaction ratio was $16.34 \%$, and the pull force was $12.80 \mathrm{Kgf}$.

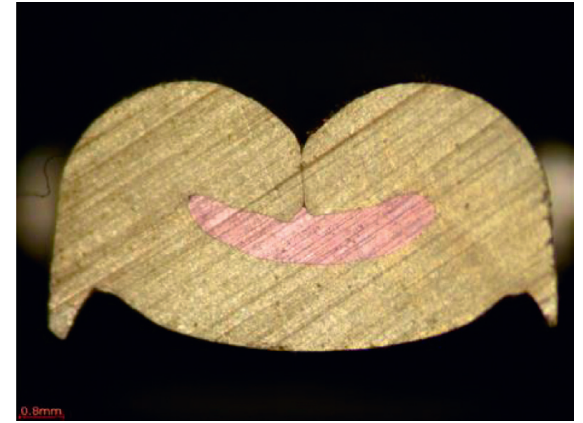

Figure 10: Crimp at a height of $1.20 \mathrm{~mm}$.

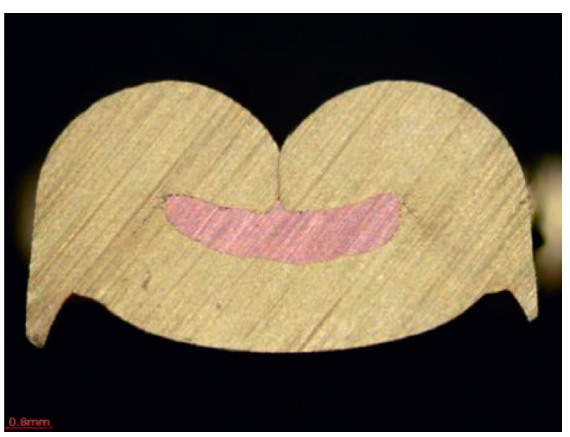

FIgURE 11: Crimp at a height of $1.25 \mathrm{~mm}$.

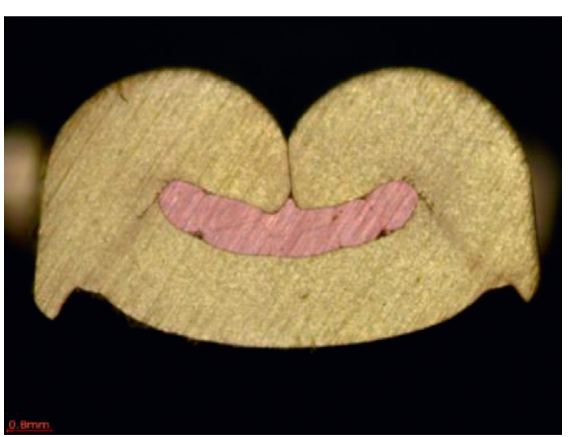

Figure 12: Crimp at a height of $1.30 \mathrm{~mm}$. 


\section{Conclusions}

The crimping process demonstrated provides a viable approach to obtain an optimum crimp and automatically outputs the test results. The system meets the requirements for detecting terminal crimping quality in the manufacturing of wiring harnesses. The system greatly reduces the intensity of labor for testing personnel, improves work efficiency, and aids to ensure the quality of the product.

Crimp quality depends on the compaction of the wires and is controlled by the dimensions of the crimp tooling, terminal wings, and cable cross-sectional area. It is thus important to note that the cable area used in production is consistent with the area of the cable used in the crimp design validation. Compaction is verified in production by terminal, cable, and crimp tool dimensions, which are typically controlled by specific tooling part numbers.

This work demonstrated the application of central composite designs with response surface methodology using the Minitab 18 Program to optimize mechanical properties of the crimping process, specifically for terminal 064 Series. ANOVA showed that the crimp variables were significantly affected by the impact pull force. Optimal crimp dimensions were a crimp height of $1.25 \mathrm{~mm}$, crimp depth of $2.36 \mathrm{~mm}$, and crimp width of $1.48 \mathrm{~mm}$, sustaining a maximum impact pull force of $13.60 \mathrm{Kgf}$ and yielding a compaction ratio of $18.63 \%$. SAE International provides standard SAE/USCAR21 Revision 4 specifying a compaction range of 15 to $20 \%$. The variation in crimp height around the optimum value of $1.25 \mathrm{~mm}$ with a tolerance of $0.05 \mathrm{~mm}$ as used in this study maintains compaction within this range for a pull force of more than $8 \mathrm{Kgf}$. This specification requires three consecutive crimp heights to pass the electrical and mechanical tests. Using samples built to this compaction range provides the best opportunity to pass such tests, whilst also addressing the problem of loose wire strands. Finally, an optimization analysis is carried out to select the finest conditions for the process.

\section{Data Availability}

The data used to support the findings of this study are included within the article.

\section{Conflicts of Interest}

The authors declare that there are no conflicts of interest regarding the publication of this paper.

\section{Acknowledgments}

This research was conducted under the support of Department of Industrial Engineering, Faculty of Engineering, Rajamangala University of Technology Thanyaburi. They are gratefully acknowledged for providing facilities and the experiment being required for this research. This research received funding from the Rajamangala University of Technology Thanyaburi.

\section{References}

[1] J. Trommnau, J. Kühnle, J. Siegert, R. Inderka, and T. Bauernhansl, "Overview of the state of the art in the production process of automotive wire harnesses, current research and future trends," Procedia CIRP, vol. 81, pp. 387-392, 2019.

[2] H. G. Nguyen, M. Kuhn, and J. Franke, "Manufacturing automation for automotive wiring harnesses," Procedia CIRP, vol. 97, pp. 379-384, 2020.

[3] L. Cepova, A. Kovacikova, R. Cep, P. Klaput, and O. Mizera, "Measurement system Analyses - gauge repeatability and reproducibility methods," Measurement Science Review, vol. 18, no. 1, pp. 20-27, 2018.

[4] I. Palomba, L. Gualtieri, R. Rojas, E. Rauch, R. Vidoni, and A. Ghedin, "Mechatronic Re-design of a manual assembly work-station into a collaborative one for wire harness assemblies," Robotics, vol. 10, no. 43, pp. 1-20, 2021.

[5] E. Aguirre and B. Raucent, "Economic comparison of wire harness assembly systems," Journal of Manufacturing Systems, vol. 13, no. 4, pp. 276-288, 1994.

[6] F. M. Ng, J. M. Ritchie, and J. E. L. Simmons, "The design and planning of cable harness assemblies," in Journal of Mechanical Science and Technology, vol. 214, no. 10, pp. 881-890.

[7] A. K. Rajak and S. D. Kore, "Application of electromagnetic forming in terminal crimping using different types of field shapers," Journal of Mechanical Science and Technology, vol. 32, no. 9, pp. 4291-4297, 2018.

[8] E. P. Simon, C. Kallmayer, M. S. Ramelow, and K. D. Lang, "Development of a Multi-Terminal Crimp Package for Smart Textile In-Tegration," in Proceedings of the 4th Electronic System-Integration Technology Conference, Amsterdam, Netherlands, September 2012.

[9] J. Y. Shim and B. Y. Kang, "Development of magnetic pulse crimping process for high durability connection terminal," Journal of Engineering Research and Application, vol. 6, no. 12, pp. 11-15, 2018.

[10] T. A. M. Castro, F. J. G. Silva, and R. D. S. G. Campilho, "Optimising a specific tool for electrical terminals crimping process," Procedia Manufacturing, vol. 11, pp. 1438-1447, 2017.

[11] H Shouming, T Qibo, and W Mei, "Crimp terminals section measurement and analysis system based on partial differential equation," The Open Automation and Control Systems Journal, vol. 7, no. 1, pp. 245-252, 2015.

[12] SAE International, Performance Specification for Cable-toTerminal Electrical Crimps. SAE/USCAR-21 4th, SAE International, U.S. and Canada, 2020.

[13] D. I. Ahmed, S. Kasolang, B. A. Khidhir, and N. R. Abdullah, "Application of response surface methodology to predict oilfilm friction in journal bearing," Applied Mechanics and Materials, vol. 393, pp. 931-937, 2013.

[14] A. Zaidon, GH. Kim, MT. Paridah, ES. Bakar, and I. Rushdan, "Optimization of the processing variables for high polymer load-ing in compressed wood using response surface methodology," Journal of Tropical Forest Science, vol. 24, no. 2, pp. 241-248, 2013.

[15] A. O. Omolola, A. I. O. Jideani, P. F. Kapila, and V. A. Jideani, "Optimization of microwave drying conditions of two banana varieties using response surface methodology," Food Science and Technology, vol. 35, no. 3, pp. 438-444, 2015.

[16] J. J. Hong and W. C. Yeh, "Application of response surface methodology to establish friction model of upset forging," 
Advances in Mechanical Engineering, vol. 10, no. 3, pp. 1-9, 2018.

[17] Á. de la Rosa, G. Ruiz, and E. Poveda, "Study of the compression behavior of steel-fiber reinforced concrete by means of the response surface methodology," Applied Sciences, vol. 9, no. 24, p. 5330, 2019.

[18] K. Senthil Kumar and K. Baskar, "Response surfaces for fresh and hardened properties of concrete with E-waste (HIPS)," Journal of Waste Management, vol. 2014, pp. 1-14, Article ID 517219, 2014.

[19] V. K. Garlapati and L. Roy, "Utilization of response surface methodology for modeling and optimization of tablet compression process," Journal of Young Pharmacists, vol. 9, no. 3, pp. 417-421, 2017.

[20] L. Donghui, L. G. Tabil, W. Decheng, W. Guanghuit, and W. Zhiqin, "Optimization of binder addition and compression load for pelletization of wheat straw using response surface methodology," International Journal of Agricultural and Biological Engineering, vol. 7, no. 6, pp. 67-78, 2014.

[21] G. E. P. Box and K. B. Wilson, "On the Experimental Attainment of Optimum Conditions," in Breakthroughs in Statistics Meth-odology and Distributionvol. 13, , pp. 270-310, Springer Series in Statistics, 1992.

[22] W. G. Cochran and G. M. Cox, Experimental Designs, Wiley, New York, 2nd Edition, 1992.

[23] J.-S. Kwak, "Application of Taguchi and response surface methodologies for geometric error in surface grinding process," International Journal of Machine Tools and Manufacture, vol. 45, no. 3, pp. 327-334, 2005.

[24] A. Azari, M. Yeganeh, M. Gholami, and M. Salari, "The superior adsorption capacity of 2,4-Dinitrophenol under ultrasound-assisted magnetic adsorption system: modeling and process optimization by central composite design," Journal of Hazardous Materials, vol. 418, Article ID 26348, 2021.

[25] A. Azari, R. Nabizadeh, A. H. Mahvi, and S. Nasseri, "Magnetic multi-walled carbon nanotubes-loaded alginate for treatment of industrial dye manufacturing effluent: adsorption modelling and process optimisation by central composite face-central design," International Journal of Environmental Analytical Chemistry, vol. 101, pp. 1-21, 2021.

[26] R. Raghupathy and K. S. Amirthagadeswaran, "Optimization of casting process based on box behnken design and response surface methodology," International Journal for Quality Research, vol. 8, no. 4, pp. 569-582, 2014.

[27] M. I. M. Kandar and H. M. Akil, "Application of design of experiment (DoE) for parameters optimization in compression moulding for flax reinforced biocomposites," Procedia Chemistry, vol. 19, pp. 433-440, 2016.

[28] M. L. Nekere and A. P. Singh, "Optimization of aluminium blank sandcasting process by using taguchi's robust design method," International Journal for Quality research, vol. 6, no. 1, pp. 81-97, 2012.

[29] R. S. Timsit and D. Ladin, "A novel crimp/compression connector technology," in Proceedings of the 65th IEEE Holm Conference, Milwaukee, USA, September 2019.

[30] F. Yang, N. Zhu, G. Liu et al., "A new method for determining the connection resistance of the compression connector in cable joint," Energies, vol. 11, no. 7, p. 1667, 2018.

[31] ASTM Standards, Standard Guide for Specification and Quality Assurance for the Electrical Contact Performance of Crimped Wire Terminations, ASTM International, Designation: B913-21, 2021.

[32] ASTM Standards, Standard Guide for Specification and Quality Assurance for the Electrical Contact Performance of
Crimped Wire Terminations, ASTM International, Designation: B942 - 21, 2021.

[33] K. E. Cramer, D. F. Perey, and W. T. Yost, "A method for the verification of wire crimp compression using ultrasonic inspection," Research in Nondestructive Evaluation, vol. 21, no. 1, pp. 18-29, 2010.

[34] S. Ogihara, K. Takata, Y. Hattori, and K. Yoshida, "Mechanical analysis of the crimping connection, electrical contacts 2006," in Proceedings of the 52nd IEEE Holm Conference on Electrical Contacts, Montreal, QC, Canada, September 2006. 